ENFOQUES JURIDICOS

REVISTA MULTIDISCIPLINAR DEL CEDEGS

ISSN 26832070

Número 03

enero-junio 2021
Artículo: "Neutralizar y castigar: una reflexión sobre el Ethos de la prisión contemporánea"

Carlos Fernández Abad

DOI: https://doi.org/10.25009/ej.v0i3.2559

\title{
Neutralizar y castigar: una reflexión sobre el Ethos de la prisión contemporánea
}

Recibido 27 julio 2020-Aceptado 19 agosto 2020.

Carlos Fernández Abad*

Universidad Rey Juan Carlos. Madrid, España carlos.abad@urjc.es

RESUMEN: Partiendo de las coordenadas teóricas expuestas por Foucault (1992) en Vigilar y Castigar, este trabajo analiza cómo ha evolucionado la naturaleza de la prisión desde sus orígenes hasta la actualidad. En este sentido, se argumenta que, desde comienzos de los años setenta del siglo pasado, se han sucedido toda una serie de profundas transformaciones económicas que han supuesto la paulatina superación de la "sociedad disciplinaria", lo que habría provocado que la prisión experimente todo un proceso de resignificación y adquiera una nueva funcionalidad que, en síntesis, estaría fundamentalmente orientada a neutralizar $e$ invisibilizar a los sectores más desprotegidos del orden social.
ABSTRACT: Starting from the theoretical foundations exposed by Foucault (1992) in Discipline and Punish, this work analyses how the nature of the prison has evolved from its origins to the present day. In this sense, it is argued that, since the beginning of the seventies of the last century, a whole series of economic changes have taken place that have led to the gradual overcoming of the "disciplinary society", which would have caused the prison to experience a whole process of resignification and acquire $a$ new functionality that, in short, would be fundamentally oriented to neutralize and make invisible the most unprotected sectors of the social order.

\footnotetext{
* Doctor en Derecho por la Universidad Rey Juan Carlos y Doctor en Sociología por la Universidade do Minho. Su tesis titulada "El sistema penitenciario en España: análisis y revisión crítica de las políticas de reinserción social", obtuvo sobresaliente cum laude por unanimidad con Mención Internacional.
}

pp. $9-21$

LEUEe 
ENFOQUES JURIDICOS

REVISTA MULTIDISCIPLINAR DEL CEDEGS

ISSN 26832070

Número 03

enero-junio 2021
Artículo: "Neutralizar y castigar: una reflexión sobre el Ethos de la prisión contemporánea"

Carlos Fernández Abad

DOI: https://doi.org/10.25009/ej.v0i3.2559
Palabras clave: Prisión; Foucault; "sociedad disciplinaria»; rehabilitación; trabajo; "sociedad excluyente».
Keywords: Prison; Foucault; "disciplinary society»; rehabilitation; work; "noninclusive society».

SUMARIO: Introducción; 1. La prisión desde la perspectiva foucaultiana; 2 . ¿Vigencia de la "sociedad disciplinaria»?: Aproximación a la crisis del ideal rehabilitador desde una lógica estructural; 3. Neutralizar y castigar: sobre el ethos de la prisión contemporánea y las funciones que esta desempeña; Conclusiones; Referencias bibliográficas

\section{Introducción}

Los años setenta del siglo pasado son generalmente señalados por la literatura especializada como un punto de inflexión en el desarrollo de la institución carcelaria (Feeley y Simon, 1992; Wacquant, 2004; Brandariz, 2007). Si, durante las décadas inmediatamente posteriores a la Segunda Guerra Mundial, el ideal rehabilitador se había constituido como el axioma central de la política penal y penitenciaria (Garland, 2005), el último tercio del siglo XX se corresponde con su progresivo desplazamiento y sustitución por otras finalidades de la pena, entre las que destacan la retribución del hecho delictivo y la neutralización del delincuente (Wacquant, 2010). Por otra parte, desde entonces y hasta aproximadamente el inicio de la crisis económica del año 2008 (Brandariz, 2014), la mayor parte de los países han experimentado un crecimiento sustancial en sus respectivos índices de encarcelamiento (Walmsley, 2016), inaugurándose una etapa que ha sido comúnmente denominada como la era del "encarcelamiento masivo» (Garland, 2001). En este sentido, el ejemplo paradigmático sería el caso de Estados Unidos: mientras que, en 1975, sus cárceles albergaban a menos de 380.000 internos, esta cifra se situó en 2.173 .800 personas durante el año 2015 (Kaeble y Glaze, 2016: 4). Todo ello, unido al hecho indiscutible de que la inmensa mayoría de los reclusos provienen de sectores de población sometidos a intensos procesos de exclusión social (De Giorgi, 2005), habrían configurado una prisión contemporánea muy determinada que, en términos provocativos, ha sido descrita por Wacquant como un gran contenedor judicial donde son arrojados los desechos de la sociedad de mercado (2010: 25 ).

El objetivo fundamental de este artículo, precisamente, estriba en examinar cómo ha evolucionado el ethos de la prisión contemporánea desde su origen hasta la actualidad. Ahora bien, a diferencia de aquellos estudios que concentran exclusivamente su interés en la prisión y sus contornos más inmediatos -como sería, por ejemplo, el campo jurídico- (Mir Puig, 1989; García-Pablos de Molina, 2010; Ríos, 2017), este trabajo busca desplazar la atención hacia el tipo de sociedad en la que la prisión contemporánea se encuentra inmersa. En este sentido, se argumenta que, desde comienzos de los años setenta del siglo pasado, la situación material que propició y fundamentó el origen de la institución carcelaria $-y$, por extensión, también de la pretensión rehabilitadora- se encuentra severamente 
ENFOQUES JURIDICOS

REVISTA MULTIDISCIPLINAR DEL CEDECS

ISSN 26832070
Artículo: "Neutralizar y castigar: una reflexión sobre el Ethos de la prisión contemporánea"

Carlos Fernández Abad

Número 03

enero-junio 2021

DOI: https://doi.org/10.25009/ej.v0i3.2559

atenuada, lo que ha propiciado que esta experimente todo un proceso de resignificación y adquiera una nueva funcionalidad que, en síntesis, estaría orientada a invisibilizar y neutralizar a los sectores más precarios del orden social.

Para enarbolar esta argumentación, en primer lugar, la prisión es sometida a todo un proceso de desnaturalización que, estando fundamentalmente inspirado en las coordenadas expuestas por Foucault (1992) en Vigilar y Castigar, permite vislumbrar las conexiones existentes entre esta pena y la «sociedad disciplinaria» en la que surge y se desarrolla. Posteriormente, tomando en consideración las profundas transformaciones acaecidas durante el último tercio del siglo $X X$, se cuestiona si la estructura social contemporánea sigue reproduciendo el modelo de la «sociedad disciplinaria». Una vez descartada esta posibilidad, el tercer apartado aborda las implicaciones de esta transición sobre la prisión y las funciones que esta desempeña. Por último, se exponen una serie de conclusiones en las que se enfatiza que, cualquier intento que aspire a transformar radicalmente la prisión contemporánea, debe pasar necesariamente por modificar la estructura excluyente en la que esta se encuentra inmersa.

\section{La prisión desde la perspectiva foucaultiana}

En la actualidad, la pena de prisión ocupa una posición de centralidad absoluta en los sistemas penales contemporáneos (Gudín Rodríguez-Magariños y Nistal Burón, 2015: 31). En este sentido, sirva como ejemplo que, en el caso español, esta pena está presente, ya sea de uno u otro modo, en el 73,39\% de los preceptos del Código Penal (Barquín Sanz y Luna del Castillo, 2012). Ahora bien, esta hegemonía no ha sido ni mucho menos constante a lo largo de la historia puesto, hasta finales del siglo XVIII y comienzos del XIX, la prisión se constituyó únicamente como un mero establecimiento de custodia donde los delincuentes esperaban a ser juzgados o sometidos a una pena de diferente naturaleza (Sanz Mulas, 2000: 179). En estos términos, durante el Antiguo Régimen, las penas más frecuentes eran las de tipo corporal, pecuniarias e infamantes, siendo la privación de libertad una opción absolutamente marginal (Ignatieff, 1978). Este hecho, por su parte, no resulta especialmente llamativo si se toma en consideración que, a diferencia de la libertad (Pavarini, 2002: 36), el cuerpo, las posesiones materiales y el honor eran los bienes más valorados por la sociedad del momento (Melossi y Pavarini, 1987: 17). Además, la penología quedaba conectada a toda una serie de características del proceso, especialmente en lo que se refiere al carácter oculto del mismo y la ejecución pública de la pena (Tamarit Sumalla et al., 2005: 31).

Sin embargo, según advierte Foucault (1992: 15 y ss.), a finales del siglo XVIII y comienzos del XIX, comienza a sucederse un doble proceso que supone una transformación radical de los métodos punitivos: mientras que, de un lado, la acción penal deja de focalizarse sobre el cuerpo del delincuente para concentrarse ahora sobre su alma -siendo entendida esta 
ENFOQUES JURIDICOS

REVISTA MULTIDISCIPLINAR DEL CEDECS

ISSN 26832070
Artículo: "Neutralizar y castigar: una reflexión sobre el Ethos de la prisión contemporánea"

Carlos Fernández Abad

Número 03

enero-junio 2021

DOI: https://doi.org/10.25009/ej.v0i3.2559

como el conjunto de hábitos y comportamientos-, el espectáculo punitivo, del otro, comienza a desaparecer de forma paulatina, relegándose la ejecución del castigo a la parte oculta del proceso. Precisamente, en este punto, se situaría el origen y el desarrollo de la pena de prisión, así como los de la pretensión de transformar al delincuente. Pero, ¿cuáles son las causas que explican esta transformación punitiva? Para una parte muy importante de la doctrina jurídico penal (García Valdés, 1982; Garrido Guzmán. 1983; Neuman, 1984), este proceso estaría íntimamente relacionado con la irrupción de la ideología humanitaria derivada del movimiento ilustrado. En este sentido, desde esta posición -que, siguiendo la terminología empleada por Baratta (2004), podría denominarse como "paradigma ideológico»-, la crítica efectuada por los Reformadores -entre otros muchos, Beccaria (2000), Howard (2000) o Bentham (1979)- se constituiría como la fuerza motriz de un proceso donde los métodos punitivos transitan desde la barbarie más absoluta hacia su progresiva humanización, siendo la prisión el resultado final de esta evolución.

Ahora bien, para otra parte importante de la literatura especializada (Rusche y Kirchheimer, 1984; Melossi y Pavarini, 1987; Foucault, 1992), esta explicación sobre el origen y el desarrollo de la pena de prisión resulta totalmente insuficiente. Como señala Foucault, "quizás se atribuyó demasiado fácilmente y con demasiado énfasis a una "humanización» que autorizaba a no analizarla" (1992: 15). En este sentido, para la "economía política de la pena», las causas que explican esta gran transformación punitiva que acontece a finales del siglo XVIII y comienzos del XIX deben buscarse en las relaciones de producción dominantes y las formas hegemónicas de organización del trabajo (De Giorgi, 2006: 57). En otras palabras, en las condiciones materiales que conforman la estructura social (Fernández Abad, 2020). Dentro de esta línea de pensamiento, la teorización esbozada por Foucault resulta especialmente sugerente. Para el autor francés, la formaprisión no es un invento del siglo XVIII sino que, más bien, su origen debe ser situado en el exterior del aparato judicial cuando, a lo largo de la "época clásica» -es decir, los siglos XVI, XVII y XVIII-, se desarrollaron toda una serie de instrumentos para obtener de los individuos el máximo de su tiempo y de sus fuerzas (1992: 233). Estos mecanismos orientados a imponer relaciones de docilidad utilidad, por su parte, serían las disciplinas, dando lugar con su generalización a lo que Foucault denomina como «sociedad disciplinaria». Pero, ¿cuáles son las causas que explican la emergencia de este tipo de sociedad?

En su explicación sobre el origen de la «sociedad disciplinaria», Foucault relaciona la emergencia de este modelo social con la presencia de un contexto histórico muy determinado: la génesis y el desarrollo del capitalismo industrial (1979: 149). En este sentido, el filósofo francés argumenta que, durante este periodo, se hizo palpable la exigencia de ajustar la correlación entre el crecimiento de los aparatos de producción y el aumento demográfico (1992: 221). A diferencia de las tecnologías de poder precedentes donde la coerción impuesta era débil y poco constante, las disciplinas, por el contrario,

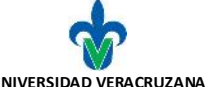

pp. $9-21$

드로 
ENFOQUES JURIDICOS

REVISTA MULTIDISCIPLINAR DEL CEDECS

ISSN 26832070
Artículo: "Neutralizar y castigar: una reflexión sobre el Ethos de la prisión contemporánea"

Carlos Fernández Abad

Número 03

enero-junio 2021

DOI: https://doi.org/10.25009/ej.v0i3.2559

permitían solucionar todo un conjunto de problemáticas asociadas a las multiplicidades humanas, convirtiendo el número en una ventaja en sí misma. De este modo, lo que subyace en este proceso no es sino la necesidad de que, bajo una subjetividad determinada que posibilite la máxima extracción de plusvalor, los individuos sean irremediablemente vinculados al aparato de producción como trabajadores. Sobre esta cuestión, es importante advertir que, tal y como se entiende en la actualidad, el trabajo es un invento de la modernidad (Gorz, 2008: 101). Es decir, en una dimensión tradicionalista, además de ser entendido como una actividad excluyente (Gorz, 1995: 26), este era concebido como un simple medio para satisfacer las necesidades vitales (Bauman, 2000: 18), no teniendo los trabajadores interiorizada la noción del «trabajo a destajo» (Weber, 2009: 70).

Ahora bien, ante el surgimiento del capitalismo, esta noción tradicionalista del trabajo se convirtió en un pesado lastre para su despegue definitivo puesto que los ex campesinos, una vez expulsados del campo y privados de sus medios de producción a través del proceso que Marx denomina como "acumulación originaria» (2007: 199), rara vez se ofrecían de forma voluntaria a participar en un régimen que les resultaba profundamente violento e incomprensible (Bauman, 2000: 26). Ante esa tesitura, fue necesario desarrollar toda una serie de estrategias que, abarcando ámbitos muy diversos -entre ellos, la política criminal-, tuvieron por finalidad vencer esta resistencia y convertir el trabajo -entendido en una dimensión reduccionista, es decir, como trabajo asalariado- en el fin que debe guiar toda existencia humana. En palabras de Foucault, "para que la esencia del hombre pueda representarse como trabajo se necesita la operación o la síntesis operada por un poder político" (1996: 138).

Precisamente, en este punto, Foucault llega al proyecto panóptico descrito por Bentham, que no solo se materializa en la prisión, sino también en toda una serie de instituciones que, guardando una elevada semejanza entre ellas, operan en su exterior, como sería el caso del cuartel, la fábrica o la escuela. Al fin y al cabo, tales instituciones cumplirían esencialmente dos funciones: mientras que, de un lado, estas acaparan el "tiempo de vida» y lo convierten en "tiempo de trabajo», del otro, la "fuerza de trabajo» es convertida al nivel de los cuerpos en "fuerza de trabajo productiva» (1996: 129). Partiendo de estas coordenadas, no resulta sorprendente que, desde sus orígenes, la pretensión rehabilitadora haya guardado una estrecha semejanza con los postulados definidos por la ética del trabajo. Es decir, el tratamiento en prisión se considera exitoso siempre y cuando, al alcanzar la libertad, la persona abandona toda pretensión delictiva y abraza el trabajo asalariado como la única forma de vida posible (Fernández Abad, 2018: 12).

En definitiva, desde esta perspectiva, el origen y el desarrollo de la prisión, así como los de la pretensión rehabilitadora, más que a la presencia de una ideología humanitaria, vendrían sobre todo determinados por la existencia de un sistema económico cuyo

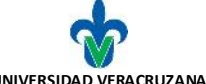

pp. $9-21$

드로 
ENFOQUES JURIDICOS

REVISTA MULTIDISCIPLINAR DEL CEDECS

ISSN 26832070
Artículo: "Neutralizar y castigar: una reflexión sobre el Ethos de la prisión contemporánea"

Carlos Fernández Abad

Número 03

enero-junio 2021

DOI: https://doi.org/10.25009/ej.v0i3.2559

crecimiento -y, por tanto, la consiguiente acumulación de capital- requiere que los cuerpos sean disciplinados. $O$, en otras palabras, que las personas sean convertidas irremediablemente en trabajadores, con todo lo que ello implica. Ahora bien, ¿es posible seguir detectando este requerimiento en la sociedad contemporánea?

\section{2. ¿Vigencia de la «sociedad disciplinaria»? Aproximación a la crisis del ideal rehabilitador desde una lógica estructural}

Según lo expuesto anteriormente, no resulta sorprendente que, durante las décadas inmediatamente posteriores a la Segunda Guerra Mundial, el ideal rehabilitador alcanzase su máximo apogeo bajo el modelo que Garland (2005) denomina como «welfarismo penal». Al fin y al cabo, este periodo no haría sino remitir a un momento histórico -comúnmente denominado como los "años dorados» del capitalismo (Hobsbawm, 1998) - donde es perfectamente identificable la base material que sustentó el origen y el desarrollo de la "sociedad disciplinaria» (Fernández Abad, 2017). Mientras que, de un lado, se puede detectar fácilmente la presencia de un sistema económico cuyo crecimiento exige que la práctica totalidad de sus miembros se conviertan en trabajadores -hasta el punto de que, si el crecimiento económico es un objetivo político de primer orden, la consecución del pleno empleo también lo es necesariamente (Bauman, 2000: 262)-, del otro, también es claramente apreciable la necesidad de (re)producir una subjetividad proletaria. Al fin y al cabo, esta etapa no haría sino remitir a una "sociedad incluyente» (Young, 2003) en la que, fundamentalmente a partir del trabajo (Zubero, 2002: 111), las personas son objeto de una asimilación continua. De este modo, resulta preciso enfatizar que la centralidad que se atribuye a la finalidad rehabilitadora es plenamente coherente con la estructura social en la que toma forma y se desarrolla.

Ahora bien, desde comienzos de los años setenta del siglo pasado, se han sucedido toda una serie de profundas transformaciones económicas que, pudiendo ser entendidas como una consecuencia directa del proyecto neoliberal (Wacquant, 2010), han alterado radicalmente la situación material descrita en el párrafo inmediatamente anterior, dando lugar a la configuración de una "sociedad excluyente» en la que, a diferencia de su predecesora, una parte de la población se ha tornado sencillamente superflua (Fernández Abad, 2020). Por una parte, debido a la concurrencia de fenómenos como la «revolución tecnológica», la internacionalización de la economía o su creciente financiarización, la vinculación entre crecimiento económico y generación de empleo se ha roto (Hobsbawm, 1998: 413). En otras palabras, el pleno empleo ya no sería una condición necesaria para sustentar la acumulación de capital (Jiménez Franco, 2013). Por otra parte, en un modelo de producción «postfordista» (De Giorgi, 2006), el mundo del empleo también ha experimentado severas transformaciones cualitativas que han cuestionado si, para la supervivencia del capital, sigue siendo pertinente la (re)producción de una subjetividad

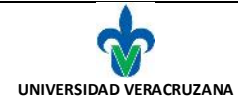

pp. $9-21$

cevey 
ENFOQUES JURIDICOS

REVISTA MULTIDISCIPLINAR DEL CEDECS

ISSN 26832070
Artículo: "Neutralizar y castigar: una reflexión sobre el Ethos de la prisión contemporánea"

Carlos Fernández Abad

Número 03

enero-junio 2021

DOI: https://doi.org/10.25009/ej.v0i3.2559

proletaria. Si, de un lado, la conversión de la flexibilidad y la precariedad en los mandatos centrales de la política económica ha supuesto que ya no se demande tanto una sujeción total al aparato productivo como una de tipo parcial (Fernández Abad, 2020), la emergencia de una "sociedad de consumidores» ha propiciado que, más que trabajadores, lo que se requiera ahora para la supervivencia del capital sea sobre todo la producción de consumidores (Bauman, 2000).

De este modo, como se puede apreciar, la situación material que sustentó la emergencia de la «sociedad disciplinaria» y, por consiguiente, de las instituciones panópticas -esto es, la necesidad de ajustar la correlación entre el crecimiento demográfico y el aumento de los aparatos de producción-, se encuentra severamente atenuada desde comienzos de los años setenta del siglo pasado. De hecho, el propio Foucault (2006), ya en sus últimos escritos, esbozó en cierta manera el agotamiento de este tipo de sociedad (Deleuze, 1995). Por el contrario, lo que se aprecia ahora es la paulatina configuración de una "sociedad excluyente» en la que, una vez que el principal elemento de inclusión social -es decir, el trabajo- es cada vez más escaso y restringido (De Giorgi, 2006), una parte importante de la población se ha tornado sencillamente superflua. En estos términos, mientras que, anteriormente, existía un interés por incluir, este ahora habría sido sustituido por las lógicas basadas en la exclusión y la expulsión. Precisamente, en este contexto y no tanto ante las problemáticas que conciernen directamente a la institución carcelaria y sus proximidades más inmediatas, deben ser leídas las profundas transformaciones que ha experimentado la prisión durante el último tercio del siglo XX (Fernández Abad, 2020).

\section{Neutralizar y castigar: sobre el ethos de la prisión contemporánea y las funciones que esta desempeña}

Por tanto, tal y como se ha argumentado en el apartado inmediatamente anterior, actualmente ya no se puede detectar la existencia de la situación material que, según el análisis esbozado por Foucault (1992), propició la emergencia de la «sociedad disciplinaria » y la consiguiente funcionalidad de las instituciones panópticas. Ahora bien, este hecho, por su parte, no ha supuesto ni mucho menos la desaparición de la prisión, sino que, más bien, esta habría experimentado todo un proceso de resignificación que, reforzando su hegemonía, ha derivado en la adquisición de una nueva funcionalidad. En este sentido, en el contexto definido por la "sociedad excluyente», la prisión ya no estaría orientada a disciplinar los cuerpos y (re)producir trabajadores, sino sobre todo a invisibilizar y neutralizar a aquellas personas que, debido a su posición en el tejido productivo, se han tornado totalmente prescindibles. En otras palabras, más que Vigilar y Castigar, ahora el ethos de la prisión contemporánea se podría resumir en Neutralizar y Castigar. En estos términos, no debe resultar especialmente sorprendente ni que, desde comienzos de los años setenta del siglo pasado, el ideal rehabilitador haya entrado en una profunda crisis ni 
ENFOQUES JURIDICOS

REVISTA MULTIDISCIPLINAR DEL CEDECS

ISSN 26832070
Artículo: "Neutralizar y castigar: una reflexión sobre el Ethos de la prisión contemporánea"

Carlos Fernández Abad

Número 03

enero-junio 2021

DOI: https://doi.org/10.25009/ej.v0i3.2559

que la hipertrofia de la población penitenciaria -y, en una dimensión más amplia, del sistema penal- haya estado presente en la mayor parte de los países de corte neoliberal (Cavadino y Dignan, 2006).

En este contexto, una vez experimentado tal proceso de resignificación, la prisión contemporánea se habría constituido como un dispositivo central para gobernar la exclusión social, no ya con la finalidad de propiciar la progresiva inclusión de estas personas sino sobre todo de asegurar su separación definitiva de la sociedad. Para ello, esta desplegaría toda una serie de funciones materiales y simbólicas que resultan cruciales para el mantenimiento y la (re)producción de la "sociedad excluyente» (Fernández Abad, 2017: 256 y ss.): en relación con las primeras, ante todo, esta institución se erigiría como un medio óptimo para invisibilizar los problemas sociales y, en su caso, neutralizar a los sectores más disruptivos del orden social. En este sentido, esta realidad queda evidenciada en el perfil sociodemográfico que comparten la inmensa mayoría de los presos. Según advierte Wacquant (2010b) sobre el caso de Estados Unidos, el hiperencarcelamiento se habría nutrido fundamentalmente de personas pobres, afroamericanas y provenientes del gueto. En los países europeos, por su parte, este habría afectado principalmente a personas de clase social baja e inmigrantes (De Giorgi, 2005). Por otra parte, Wacquant también señala que, si se toma en consideración la contracción que ha experimentado el ala social del Estado, la prisión habría actuado también como un mecanismo orientado a imponer el trabajo desocializado a los sectores más desprotegidos, de modo que, ante la ausencia de cualquier otra forma de supervivencia, la única forma de evitar ser encarcelado pasaría por aceptar cualquier trabajo, independientemente de lo precario que este sea (2010: 163).

Por otra parte, en relación con las funciones simbólicas de la prisión, es importante tomar en consideración que otra de las modificaciones más importantes que han experimentado las sociedades contemporáneas durante el último tercio del siglo XX se refiere a la pérdida de soberanía que han sufrido los Estados en materia económica como consecuencia de la globalización (Bauman, 2002). Este hecho, por su parte, ha motivado que los Estados tengan que demostrar su poderío en otras áreas, siendo la delincuencia fundamentalmente la callejera- un ámbito especialmente apropiado para ello (Cheliotis, 2014). En este sentido, el uso expansivo de la prisión habría servido para aplacar la inseguridad que experimenta la población, aunque el origen de la misma provenga más de factores relacionados con la desregulación económica que con el fenómeno criminal (Wacquant, 2010). En otras palabras, a través de la identificación de toda una serie de "enemigos cómodos» (Christie, 1986), la prisión permitía desplazar las verdaderas causas de ansiedad hacia otras en la que el Estado tiene una mayor capacidad -o, más bien, voluntad- de actuación.

Además, la prisión también serviría para crear categorías de percepción públicas que, volviéndose reales en sus consecuencias, no solo permiten crear enemigos sobre los cuales

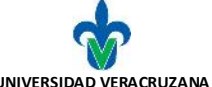

pp. $9-21$

드로 
ENFOQUES JURIDICOS

REVISTA MULTIDISCIPLINAR DEL CEDECS

ISSN 26832070

Número 03

enero-junio 2021
Artículo: “Neutralizar y castigar: una reflexión sobre el Ethos de la prisión contemporánea"

Carlos Fernández Abad

DOI: https://doi.org/10.25009/ej.v0i3.2559

descargar la ansiedad acumulada sino también reforzar las divisiones materiales. Es decir, a partir de la sinergia establecida entre el sistema penal y los medios de comunicación (Soto Navarro, 2005), se asiste a la generación de toda una serie de conceptos y discursos que terminan por atribuir una peligrosidad intrínseca a categorías enteras de individuos $y$, en consecuencia, legitimar su control y neutralización (Cheliotis, 2014: 92). Este hecho, por ejemplo, puede apreciarse claramente en la relación que, sin ninguna base empírica (González Sánchez, 2016), se ha establecido entre la delincuencia y la raza -o, en el caso europeo, el hecho de ser migrante-, lo que ha contribuido a orientar la política criminal en esta dirección y, en consecuencia, reforzar las divisiones materiales existentes.

En definitiva, debido al carácter excluyente de la estructura social en la que se encuentra inmersa, la prisión habría pasado de ser una institución orientada -al menos teóricamentea la rehabilitación del delincuente a otra en la que el interés principal reside en su pura invisibilización y neutralización, sufriendo una importante transformación en su ethos.

\section{Conclusiones}

De este modo, como se ha podido apreciar a lo largo de este trabajo, las profundas transformaciones que ha experimentado la prisión a raíz del último tercio del siglo XX se relacionan con la emergencia de una "sociedad excluyente» en la que, a diferencia de su predecesora, ya no es posible detectar los fundamentos materiales que propiciaron la existencia de la «sociedad disciplinaria». En estos términos, conviene enfatizar que, más que incidir sobre la prisión y sus contornos más inmediatos, cualquier proyecto de reforma que aspire a transformar radicalmente la prisión contemporánea y devolver a una posición de centralidad las lógicas penales basadas en la inclusión debe pasar necesariamente por revertir el carácter excluyente de la estructura social. Para ello, no solo existe la opción de retornar a la centralidad del empleo, sino que también se pueden explorar otras alternativas, como sería, por ejemplo, el caso de la Renta Básica Universal. 
ENFOQUES JURIDICOS

REVISTA MULTIDISCIPLINAR DEL CEDECS

ISSN 26832070

Número 03

enero-junio 2021
Artículo: "Neutralizar y castigar: una reflexión sobre el Ethos de la prisión contemporánea"

Carlos Fernández Abad

DOI: https://doi.org/10.25009/ej.v0i3.2559

\section{Fuentes de consulta}

Baratta, A. (2004). Criminología Crítica y crítica del Derecho Penal. Introducción a la sociología jurídico-penal. Buenos Aires: Siglo XXI Editores Argentina.

Barquín Sanz, J. y Luna del Castillo, J. (2012). “En los dominios de la prisión. Distribución numérica de las penas en el Código y en la justicia penal". Revista Electrónica de Ciencia Penal y Criminología, n.o. 14 (16), pp. 1-52.

Bauman, Z. (2000). Trabajo, consumismo y nuevos pobres. Barcelona: Gedisa.

Bauman, Z. (2002). Modernidad líquida. Buenos Aires: Fondo de Cultura Económica Argentina.

Beccaria, C. (2000). De los delitos y las penas. México: Fondo de Cultura Económica.

Bentham, J. (1979). El panóptico. Madrid: La Piqueta

Brandariz García, J. A. (2007). Política criminal de la exclusión: el sistema penal en tiempo de declive del Estado social y de crisis del Estado-nación. Granada: Comares.

Brandáriz García, J. A. (2014). "La evolución de la penalidad en el contexto de la Gran Recesión: la contracción del sistema penitenciario español". Revista de Derecho Penal y Criminología, n.‥12, pp. 309-342.

Cavadino, M. y Dignan, J. (2006). "Penal Policy and political Economy". Criminology and Criminal Justice, vol. 6 (4), pp. 435-456.

Cheliotis, L. (2014). “Gobernar a través del espejo. Neoliberalismo, gerencialismo y psicopolítica del control de la desviación". Crítica penal y poder, n.․․ 6, pp. 66-109.

Christie, N. (1986). "Suitable enemy". En Bianchi, R. y Von Swaaningnen, R. (eds.), Abolitionism: toward a non-repressive approach to crime. Amsterdam: Free University Press.

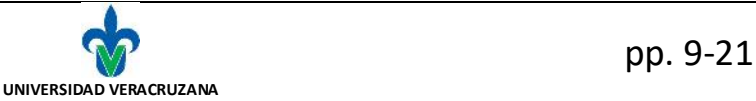


ENFOQUES JURIDICOS

REVISTA MULTIDISCIPLINAR DEL CEDECS

ISSN 26832070

Número 03

enero-junio 2021
Artículo: "Neutralizar y castigar: una reflexión sobre el Ethos de la prisión contemporánea"

Carlos Fernández Abad

DOI: https://doi.org/10.25009/ej.v0i3.2559

De Giorgi, A. (2005). Tolerancia cero. Estrategias y prácticas de la sociedad de control. Barcelona: Virus Editorial.

De Giorgi, A. (2006). El gobierno de la excedencia. Postfordismo y control de la multitud. Madrid: Traficantes de Sueños.

Deleuze, G. (1995). Conversaciones. Valencia: Pre-textos.

Feeley, M. y Simon, J. (1992). "The new penology: notes on the emerging strategy of corrections and its implications". Criminology, vol. 30, n.o. 4, pp. 449-474.

Fernández Abad, C. (2017). “La resignificación de la pena de prisión y su renovada funcionalidad en el contexto de la "sociedad excluyente»: aproximación crítica al desplazamiento del ideal resocializador desde una lógica estructural". Revista de Derecho Penal y Criminología, n.18, pp.217-263.

Fernández Abad, C. (2018). (Re)interpretando la crisis de la resocialización como rasgo definitorio de la prisión contemporánea: una aproximación a sus causas y posibilidades reales". ENCRUCIJADAS. Revista Críticas de Ciencias Sociales, vol.16, pp.1-19.

Fernández Abad, C. (2020). Transformar la prisión desde la estructura. Una aproximación a las potencialidades de la Renta Básica Universal. Granada: Comares.

Foucault, M. (1979). El ojo del poder. Madrid: La Piqueta.

Foucault, M. (1992). Vigilar y castigar. Nacimiento de la prisión. Madrid: Siglo XXI.

Foucault, M. (1996). La verdad y las formas jurídicas. Barcelona: Gedisa.

Foucault, M. (2006). Seguridad, territorio y población. Buenos Aires: Fondo de Cultura Económica.

García-Pablos de Molina, A. (2010). "Sobre la función resocializadora o rehabilitadora de la pena". Cuadernos de Política Criminal, n.‥100, pp. 77-91.

Garland, D. (2001). Mass imprisonment: social causes and consequences. London: Sage.

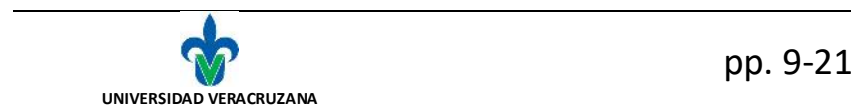


ENFOQUES JURIDICOS

REVISTA MULTIDISCIPLINAR DEL CEDECS

ISSN 26832070

Número 03

enero-junio 2021
Artículo: "Neutralizar y castigar: una reflexión sobre el Ethos de la prisión contemporánea"

Carlos Fernández Abad

DOI: https://doi.org/10.25009/ej.v0i3.2559

Garland, D. (2005). La cultura del control. Crimen y orden social en la sociedad contemporánea. Barcelona: Gedisa.

Garrido Guzmán, L. (1983). Manual de Ciencia Penitenciaria. Madrid: Publicaciones del Instituto de Criminología de la Universidad Complutense de Madrid.

González Sánchez, I. (2016). "La penalización de los migrantes: irregularidad y cárcel en la construcción del estado neoliberal". Migraciones, n.o.39, pp.123-147.

Gorz, A. (1995). Metamorfosis del trabajo. Búsqueda de sentido. Crítica de la razón económica. Madrid: Editorial Sistema.

Gorz, A. (2008). "La crisis de la idea de trabajo y la izquierda postindustrial". En Valdivielso, J. (ed.) Antología André Gorz. Crítica de la razón productivista (101-120). Madrid: Los Libros de la Cátara.

Gudín Rodríguez-Magariños y Nistal Burón, J. (2015). La historia de las penas. De Hammurabi a la cárcel electrónica. Valencia: Tirant lo Blanch.

Hobsbawm, E. (1998). Historia del siglo XX. Buenos Aires: Crítica.

Howard, J. (2000). The state of the prisons in England and Wales, with preliminary observations, and an account of some foreign prisons. Londres: The British Library.

Ignatieff, M. (1978). A just measure of pain. The penitentiary in the industrial revolution 1750-1850.Londres: The Macmillan Press.

Jiménez Franco, D. (2013). La burbuja penal. Mercado, estado y cárcel en la democracia española. Tesis doctoral. Departamento de Derecho Penal, Filosofía del Derecho e Historia del Derecho, Zaragoza, Universidad de Zaragoza.

Kaeble, D. y Glaze, L. (2016). “Correctional populations in the United States, 2015”. Bureau of Justice Statistics, diciembre, pp. 1-20.

Marx, K. (2007). El Capital. Libro I - Tomo III. Madrid: AKAL.

Melossi, D. y Pavarini, M. (1987). Cárcel y fábrica: los orígenes del sistema penitenciario. México: Siglo XXI.

pp. $9-21$

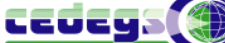


ENFOQUES JURIDICOS

REVISTA MULTIDISCIPLINAR DEL CEDECS

ISSN 26832070

Número 03

enero-junio 2021
Artículo: "Neutralizar y castigar: una reflexión sobre el Ethos de la prisión contemporánea"

Carlos Fernández Abad

DOI: https://doi.org/10.25009/ej.v0i3.2559

Mir Puig, S. (1989). ¿Qué queda en pie de la resocialización? Eguzkilore: Cuaderno del Instituto Vasco de Criminología, n.o.2, pp.35-41.

Neuman, E. (1984). Prisión abierta: un estudio preliminar. Buenos Aires: Depalma.

Pavarini, M. (2002). Control y dominación: teorías criminológicas burguesas y proyecto hegemónico. Buenos Aires: Siglo XXI Editores.

Ríos Martín, J. C. (2017). Cuestiones de Política Criminal. Funciones y miserias del sistema penal. Granada: Comares

Sanz Mulas, N. (2000). Alternativas a la pena privativa de libertad (análisis crítico y perspectivas de futuro en las realidades española y centroamericana). Madrid: Colex.

Soto Navarro, S. (2005). "La influencia de los medios en la percepción social de la delincuencia". Revista Electrónica de Ciencia Penal y Criminología, n.‥ 07(09), pp. 146.

Wacquant, L. (2004). Las cárceles de la miseria. Buenos Aires: Argentina.

Wacquant, L. (2010). Castigar a los pobres. El gobierno neoliberal de la inseguridad social. Barcelona: Gedisa.

Wacquant, L. (2010b). "Estigma racial en la construcción del estado punitivo norteamericano". Astrolabio, n.o. 5, pp. 145: 159.

Walmsley, R. (2016). "World prison population list". Institute for Criminal Policy Research, pp. 1-15.

Weber, M. (2009). La ética protestante y el espíritu del capitalismo. Madrid: Editorial Reus.

Young, J. (2003). La sociedad excluyente: exclusión social, delito y diferencia en la modernidad tardía. Madrid: Marcial Pons.

Zubero, I. (2002). “Repensar el empleo, repensar la vida”. En Reventós, D. (coord.), Renta Básica. Por una ciudadanía más libre, más igualitaria y más fraternal (pp. 109-125). Barcelona: Ariel.

universidad veracruzana p. $9-21$ 